\title{
BASQUETE DE RUA NA CIDADE DO RIO DE JANEIRO
}

\author{
Anlessa Cristine Almeida de Jesus \\ Universidade Gama Filho, Rio de Janeiro, Rio de Janeiro, Brasil \\ Sebastião Votre \\ Universidade Gama Filho, Rio de Janeiro, Rio de Janeiro, Brasil
}

\begin{abstract}
Resumo
O estudo tem por objetivo identificar a origem e descrever o cenário do basquete de rua no Rio de Janeiro. A pesquisa é de leve orientação etnográfica. Com base nos registros do diário de campo, das falas dos jogadores e de um informante de elite, constatamos que o basquete de rua é praticado majoritariamente na periferia da cidade. Concentramo-nos no espaço esportivo coordenado pela Central Única das Favelas (Cufa), no Viaduto de Madureira, onde a cada semana se encontram jogadores de diversos bairros e onde as regras sintetizam e reinterpretam as normas de outros espaços em que se pratica essa modalidade de basquete. A modalidade vem perdendo espaço para os projetos de futebol.
\end{abstract}

Palavras-chave: Etnografia. Jogo. Participação.

\section{Introdução}

$\mathrm{O}$ basquete surgiu em 1891, em Massachusetts, nos Estados Unidos da América (FREITAS; VIEIRA, 2006). Em 1936, foi incluído nos Jogos Olímpicos de Verão, quando obteve grande aceitação, passando a ser um dos esportes mais assistidos durante os jogos. Nos Estados Unidos, o esporte se popularizou rapidamente, ganhando adeptos em todos os estados; atualmente, conta com duas ligas profissionais, a National Basketball Association Development League (NBDL) e a National Basketball Association (NBA), além das universitárias. $\mathrm{Na}$ atualidade, ao lado do basquete profissional, o streetball se mundializou e é praticado nas ruas e praças, com algumas características distintas do basquete convencional. No Brasil, o esporte consagrou-se como basquete de rua.

Parte das jogadas de efeito no basquete de rua provém dos Harlem Globetrotters. O primeiro time foi formado em 1927, por Abe Sapers- 
tein, proprietário do salão de dança Savoy Ballroom, no Harlem, em Nova Iorque. Ele criou o time de basquete para, após as apresentações de música, continuar ganhando dinheiro e distraindo o público. Após alguns anos, os atletas saíram em turnê pelos Estados Unidos, fazendo apresentações de basquete. Até hoje seus sucessores percorrem o mundo com apresentações de basquete espetáculo ${ }^{1}$. Continuam explorando e aperfeiçoando suas habilidades, dando ênfase às jogadas de efeito, estilizadas, para atrair a atenção do público.

Os jogadores que demonstram suas habilidades por meio de jogadas e manobras de efeito são chamados de ballers, pois são artistas habilidosos no que fazem com a bola nas mãos. As habilidades são marcadas pelas manobras, que empolgam as torcidas e estimulam o marcador adversário a retribuir na próxima jogada, acirrando a disputa pela habilidade. Segundo Silva e Correia (2008), os jogadores de playgrounds incorporaram a linguagem corporal dos Harlem Globetrotters e criaram uma série de movimentos típicos do jogo, inimagináveis antes deles.

Este estudo tem por objetivo descrever a origem e o panorama do basquete de rua no Rio de Janeiro, tomando como local de concentração dos jogadores e cenário da etnografia o Centro Esportivo e Cultural da Central Única das Favelas (Cufa), embaixo do Viaduto Negrão de Lima, em Madureira, na rua Alfeu Faria Castro, s/n, na zona norte da cidade.

O levantamento da literatura sobre basquete de rua evidenciou uma lacuna na produção de ensaios e artigos originais na área. Pinheiro (2009) descreve e analisa as atividades artísticas e esportivas associadas aos eventos do Prêmio Hutúz de hip hop e a Liga Brasileira de Basquete de Rua. Silva e Correia (2008) estudaram o basquete de rua a partir de duas questões norteadoras: analisar as racionalidades dos grupos envolvidos com essa prática, que se insere no movimento cultural do hip hop, e discutir as tendências das estruturas de comunicação e informação, ao abordar a dimensão do espetáculo que se revela nessas novas linguagens esportivas. Estudos pontuais têm identificado o basquete de rua com aspectos das culturas locais, como o de Duarte (2010), que buscou identificar as características do basquete de rua como manifestação da cultura corporal negra em Salvador. A trajetória

1-Disponível em: <http://www.harlemglobetrotters.com/history/timeline/>. Acesso em: 20 abr. 2011.

Pensar a Prática, Goiânia, v. 15, n. 4, p. 821-1113, out./dez. 2012 
histórica do basquete de rua nos Estados Unidos e no Brasil foi apresentada por Oliveira Filho (2006), que ressaltou as especificidades das normas de cada país.

A referência técnica para este estudo é o "Manual dos basqueteiros", que foi escrito e divulgado pela Cufa em 2008. O manual apresenta uma tradução das regras de streetball adaptadas ao campeonato brasileiro da entidade. Refere também outros elementos da cultura negra, como hip hop e dança, com foco nas normas para conduta nas disputas de basquete de rua.

$\mathrm{Na}$ temática de esportes para a juventude, podemos citar Spindola (2008) e Osborne, Silva e Votre (2011). Na temática da etnografia do esporte na cidade, consultamos Stigger (2007). Para a etnografia urbana, acolhemos as contribuições de Magnani (2002).

\section{O basquete de rua}

Segundo Oliveira Filho (2006), o streetball emergiu nas praças e ruas dos bairros da periferia das grandes cidades americanas, sempre jogado ao som do hip hop. É associado ao movimento hip hop, também nascido nas ruas dos bairros pobres nos Estados Unidos, na década de 1970, em decorrência da exclusão social da população americana de baixa renda.

$\mathrm{O}$ basquete de rua tem como característica os movimentos, que se tornam mais importantes do que a marcação da própria cesta. São mais valorizados o estilo, a habilidade e a criatividade do jogador do que a altura para o jogo e a marcação da cesta, pois as jogadas de efeito são o ponto alto do esporte, com o uso de recursos para "desconsertar" o adversário.

A modalidade dá ao jogador a liberdade de criar e improvisar jogadas, podendo haver diferentes formações, como: 1 x 1, 3 x 3 e Freestyle (jogadores que disputam competições de malabarismos com a bola). Diferentemente do basquete tradicional, é jogado apenas em meia quadra, tendo apenas uma tabela (OLIVEIRA FILHO, 2006).

De acordo com o que observamos, utilizam-se as regras básicas do basquete convencional, com o adendo do espetáculo: desenvolver jogadas que provoquem a reação dos oponentes e da torcida. A tabela e $\mathrm{o}$ aro têm o tamanho normal exigido no basquetebol de quadra pela Federação Internacional de Basquetebol, mas a altura da cesta é de 3,7 $\mathrm{cm}$, e não de $3,05 \mathrm{~m}$. A quadra não possui um tamanho específico. A 
Cufa recomenda que seja de 12 por $22 \mathrm{~m}$, mas sua própria quadra, em Madureira, mede 16 por $22 \mathrm{~m}$.

\section{O hip hop e o basquete de rua}

O basquete de rua está associado ao movimento hip hop e é praticado ao som do rap (rhythm and poetry). O jogo e o som andam juntos, sendo as jogadas embaladas pelo ritmo que anima a torcida e os jogadores durante as partidas dos eventos esportivos. O disk jockey (DJ), responsável pela propagação do ritmo, dita o andamento da partida com suas músicas mixadas; quando toca uma música animada, os torcedores se entusiasmam e os jogadores se empolgam, procurando desenvolver mais jogadas de efeito para receber o clamor da torcida, que os incentiva a criar jogadas espetaculares.

Outro elemento vinculado ao movimento hip hop é o master of ceremony (MC), que precisa estar em sintonia com a quadra, mantendo a atenção nos lances do jogo e estimulando a torcida. Nos campeonatos de basquete de rua, muitas vezes é o MC que incita o jogador a realizar jogadas de efeito ou a utilizar a marcação individual, promovendo a demonstração das habilidades individuais.

O hip hop nasceu no final da década de 1970, para que afro-americanos e caribenhos pudessem reelaborar suas práticas culturais e produzir, através da arte, uma interpretação das novas condições socioeconômicas postas pela vida urbana (GUARESCHI; MORAES; PRATES, 2008). Como elementos do movimento hip hop, nasceram o rap, o grafite, o break, o MC e o DJ. Juntos, esses estilos tornaram-se os pilares da cultura hip hop, fazendo da rua o espaço privilegiado da expressão cultural dos jovens negros e pobres (DAYRELL, 2002). O movimento expressa sentimentos de protesto por parte dos cantores contra os governos e seus sistemas. Consagrou-se como uma das manifestações culturais que apresentam os problemas sociais em forma de música e dança

No Brasil, o movimento chegou na década de 1980 nas periferias das cidades e denunciou aos ouvintes as mazelas e condições vividas pelos jovens de comunidades menos favorecidas (OLIVEIRA FILHO, 2006).

Pensar a Prática, Goiânia, v. 15, n. 4, p. 821-1113, out./dez. 2012 


\section{Método}

O estudo é de caráter levemente etnográfico. Segundo Stigger (2007), o trabalho etnográfico é o resultado da interpretação de padrões culturais de um contexto específico desenvolvido pelo investigador a partir das representações que determinados indivíduos e grupos sociais fazem das suas práticas. Incorporamos as técnicas da observação participante ${ }^{2}$, com registros em diário de campo, para levantar pistas que confirmassem ou corrigissem o que foi observado no campo. Procuramos utilizar a perspectiva de Magnani (2002), identificando, descrevendo e interpretando as práticas que ocorrem na modalidade no Rio de Janeiro.

Fizemos uma entrevista em profundidade, com um informante de elite, considerado como referência pelos basqueteiros. Esse entrevistado foi o responsável pela introdução do basquete de rua no Rio de Janeiro.

O projeto de pesquisa foi submetido ao Comitê de Ética em Pesquisa (CEP) da Universidade Gama Filho ${ }^{3}$. Após a sua aprovação, foi iniciada a coleta de dados, mediante assinatura de Termo de Consentimento Livre e Esclarecido pelos participantes das peladas na quadra oficial da Cufa.

Para os efeitos do estudo, foram realizadas 15 visitas ao Centro Esportivo e Cultural da Cufa, embaixo do Viaduto Negrão de Lima, em Madureira, zona norte da cidade e ponto de convergência dos jogadores de basquete de rua.

2-A autora principal nasceu em Lins de Vasconcelos e foi criada na favela do Urubu, localizada no bairro da Abolição, zona norte do município do Rio de Janeiro. Iniciou suas atividades esportivas na quinta série do ensino fundamental, como atleta de futebol e de handebol. Em 2002 iniciou sua carreira no basquetebol, tornando-se árbitra da Federação Estadual de Basquetebol do Rio de Janeiro. Em 2004 iniciou sua caminhada no basquete de rua, como árbitra, participando dos principais campeonatos organizados pela Cufa nos âmbitos municipal, estadual e nacional. Participou também como árbitra do amistoso internacional organizado pela entidade, em que pelo Brasil jogaram os Reis das Ruas, que constituem a seleção dos melhores jogadores de basquete de rua.

3-CEP, CAAE.0001.0312.000-11.

Pensar a Prática, Goiânia, v. 15, n. 4, p. 821-1113, out./dez. 2012 


\section{Basquete de rua no Rio de Janeiro}

Duas organizações sociais são responsáveis pelo início da visibilidade do basquete de rua no Rio de Janeiro. A primeira é a Liga Urbana de Basquete (LUB), presidida por Asfilófio de Oliveira Filho, que herdou materiais voltados para a prática de basquete, após um encontro promovido pela NBA, em 2004, quando seus jogadores vieram realizar ações sociais na América Latina. De posse desse material, ele criou um projeto voltado para o basquete de rua. Promoveu uma chamada a que responderam e se inscreveram 200 jogadores de basquete da cidade; selecionou 15 deles e iniciou um projeto social, voltado para a modalidade, formando a LUB.

Com o time, Asfilófio percorreu o Rio de Janeiro fazendo apresentações de basquete, na linha dos Globetrotters, mas sem desafiar os outros times de basquete. $\mathrm{O}$ seu grupo de jogadores se apresentou em hospitais, escolas e comunidades carentes, mostrando o basquete de rua e exibindo as suas habilidades. De acordo com Asfilófio, que é nosso informante de elite, a LUB passou a contar com o técnico Alberto Bial, que atuava no basquete tradicional.

A segunda ONG é a Central Única das Favelas (Cufa), que foi fundada por Nega Gizza, MV Bill e Celso Athayde, em 1999. No ano de 2002, a Cufa realizou o seu primeiro campeonato de basquete de rua. O campeonato era realizado durante o evento conhecido como Hutúz Rap Festival; os jogos aconteciam durante o festival de hip hop e era denominado Hutúz Basquete de Rua. O festival, apesar de ser um sucesso, "se tornou pequeno", na opinião dos organizadores.

Em 2005, a Cufa organizou seu primeiro campeonato brasileiro de basquete de rua, a Liga Brasileira de Basquete de Rua (Libbra). Após o primeiro campeonato da Cufa e o projeto social promovido pela LUB, a modalidade ganhou visibilidade, suporte do governo do estado e uma estrutura institucionalizada no Rio de Janeiro.

Em 2010 vimos a presença maciça de praticantes do país e do Rio de Janeiro no campeonato nacional realizado pela Cufa, com 576 jogadores inscritos, divididos em 96 times, que vieram de todas as partes do Brasil, para disputar as etapas do campeonato nacional no Rio de Janeiro. Entre os estados participantes estavam Tocantins, Rio de Janeiro, São Paulo, Mato Grosso, Rio Grande do Sul, Minas Gerais, Pernambuco, Bahia, Espírito Santo, Paraná, Pará e Paraíba, além de Distrito Federal. Para participar das etapas finais do campeonato naci- 
onal promovido pela organização, todos esses times tiveram que participar de seletivas estaduais. Na seletiva estadual do Rio de Janeiro, houve em média 200 jogadores envolvidos. Os jogos duraram quatro semanas, sempre aos sábados, com cerca de 15 times por dia participando do campeonato.

O campeonato nacional também contempla o público feminino e juvenil, porém em menor número de equipes participantes em relação às equipes masculinas. Essas modalidades não participam de seletivas em seus estados, sendo as equipes criadas pelos jogadores e inscritas no torneio.

O primeiro jogo internacional de basquete de rua ocorreu em Barueri (SP), em 2008. Tendo a equipe do Chile como adversário, o evento, denominado Reis da Rua, teve a vitória do combinado brasileiro. Os melhores jogadores do campeonato nacional de 2008 foram selecionados para fazer parte da equipe brasileira.

Em 2009 a Cufa criou a Liga Internacional de Basquete de Rua ${ }^{4}$, abrangendo assim um circuito mundial da modalidade denominado Reis da Rua. A organização social promoveu também um circuito europeu de basquete de rua, com países que viriam ao Brasil participar do campeonato mundial que seria sediado pelo estado do Rio de Janeiro. O evento ainda está em processo de organização.

Em 2011, a Cufa está presente em todos os 27 estados brasileiros e em 20 países do mundo e é reconhecida por trabalhar com políticas sociais, culturais e esportivas. Todos os 27 estados brasileiros possuem eventos de basquete de rua durante o ano, organizados pela entidade.

No Rio de Janeiro, o basquete de rua é praticado nas comunidades das periferias, com times formados por negros, com idade entre 19 e 34 anos. Durante a pesquisa, identificamos 14 comunidades onde é jogada a modalidade: Cavalcanti, Curicica, Cidade de Deus, Jardim América, Cezarão, Rocinha, Cruzada São Sebastião, Guadalupe, Vila Valqueire, Anchieta, Padre Miguel, Taquara, Bangu e Madureira. Dessas comunidades, sete estão localizadas na zona norte da cidade. Seis se localizam na zona oeste e duas na zona sul da cidade. Assim como nos Estados Unidos, no Rio de Janeiro a modalidade também se concentra nas periferias.

4-Após a idealização da Liga Internacional de Basquete de Rua, a entidade abandonou o termo original Libbra e adotou o novo termo para seus campeonatos, organizados em níveis municipais, estaduais e nacionais.

Pensar a Prática, Goiânia, v. 15, n. 4, p. 821-1113, out./dez. 2012 


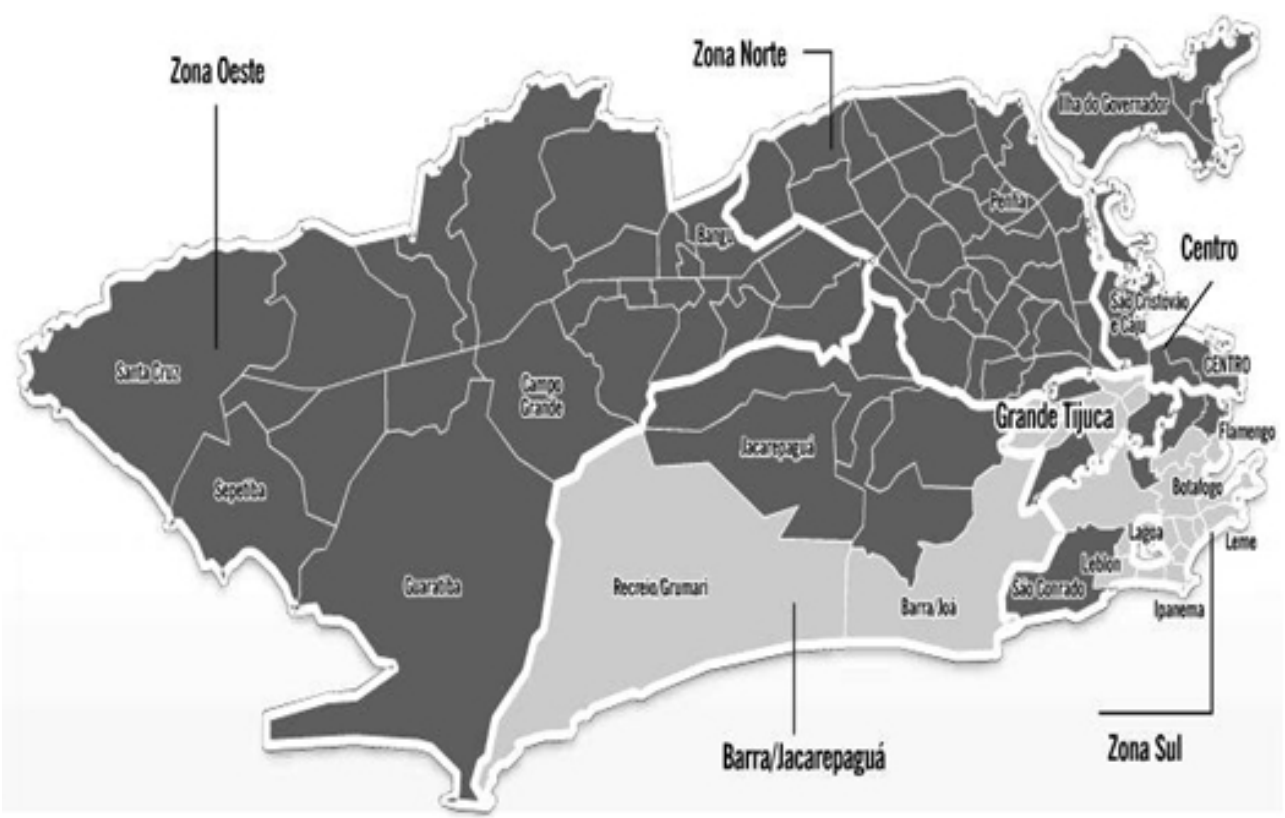

Fonte: http://butecodoedu.blogspot.com/2010_11_01_archive.html

No Aterro do Flamengo, há campeonatos realizados por empresas de roupas, com a finalidade de promover produtos voltados para a prática do basquete. Alguns eventos são organizados pelos próprios jogadores, a exemplo do $1^{\circ}$ de Maio, campeonato realizado na Baixada Fluminense há mais de dez anos.

\section{Quem são, de onde são e o que pensam os que jogam basquete nas ruas no Rio de Janeiro}

Durante as visitas, o acolhimento foi muito bom, pois a primeira autora é árbitra de basquete de rua e coopera nas competições em que se requer a presença de árbitro. Conversamos com os jogadores sobre o esporte praticado na cidade, os locais onde é praticado e as particularidades de alguns locais. Descobrimos que a idade média dos jogadores é de 25 anos e o tempo de prática varia entre 3 e 19 anos. Interagimos mais de perto com 8 praticantes que são mais assíduos, praticam a modalidade de 2 a 4 vezes por semana, chegando a ficar no mínimo 4 e no máximo 6 horas jogando basquete, dependendo do local onde forem jogar.

Saem de diversas comunidades da cidade para se encontrar em Madureira, cujo espaço é aberto às terças e quintas-feiras sempre das $20 \mathrm{~h}$ às $24 \mathrm{~h}$. A quadra é bem cimentada, plana, limpa e bem iluminada, 
organizada com os equipamentos específicos para a prática do basquete, em perfeito estado; é cercada por mureta de concreto para a bola não ultrapassar os limites e atrapalhar as oficinas que ocorrem ao lado; nas linhas de fundo, possui redes, que vão do teto do viaduto até o chão; tem demarcação bem sinalizada; constitui um excelente espaço público voltado para as práticas esportivas. No espaço ocorrem também oficinas de futebol, basquete, DJ, skate e grafite. O complexo sob o viaduto possui uma área média de $800 \mathrm{~m}^{2}$.

O bairro de Madureira se tornou símbolo do basquete de rua após a Cufa iniciar a realização de seus campeonatos de âmbito nacional e estadual nessa quadra. Madureira também é conhecida por promover o maior evento de black music da cidade, o "baile do viaduto", que acontece todo sábado à noite, embaixo de outra parte do viaduto Negrão de Lima, e reúne fãs da música negra do Rio de Janeiro. Os adeptos do rhythm and blues (R\&B), hip hop e rap se encontram para curtir o baile que já existe há 20 anos. Os jogadores de basquete de rua no Rio de Janeiro, que costumam jogar ao som do hip hop, também se encontram, nos fins de semana, para frequentar o baile do viaduto; além disso, eles organizam festas e churrascos entre eles.

Enquanto aguardam sua hora de jogar, os jogadores se aglomeram nas laterais da quadra, conversando sobre diversos assuntos ligados ao basquete na cidade e ao basquete internacional, principalmente à NBA. Alguns desses jogadores foram atletas de basquete de quadra e chegaram a ser inscritos em federações, mas não se tornaram jogadores profissionais, enquanto outros nunca chegaram a jogar em clubes.

Fomos também a dois locais onde ocorrem as peladas. Percorrendo esses locais constatamos que os jogadores de cada comunidade formam os times que os representam nos campeonatos locais e nacionais. As comunidades possuem suas próprias regras, que devem ser seguidas quando um grupo de fora vai jogar em sua quadra. Eles usam o basquete tradicional como modelo, mas o adaptam em seus jogos. As regras existentes na quadra de Madureira foram criadas pelos próprios jogadores, que limitaram o número de participantes para quatro em cada time, por conta da medida da quadra.

A formação dos times se dá pelo chute de lance livre, sendo que aqueles que acertam formam os primeiros times, e os que chegam depois vão se organizando para entrarem no lugar do time perdedor da primeira partida. Durante os jogos, alguns jogadores assumem a posição de líderes do time. Esses líderes, em alguns momentos, ditam o 
andamento da partida, impedindo que alguém atrapalhe o jogo. As faltas são pedidas pelos jogadores que as sofrem e, dependendo da seriedade desses jogadores e da intensidade delas, podem haver discussões acaloradas.

Em algumas comunidades há o sistema de rodízio, para evitar que alguns times fiquem mais fortes que os outros. Os jogadores que chegam depois das partidas iniciadas colocam o nome em um caderno e vão entrando no jogo de acordo com a ordem de chegada, controlada pelo nome no caderno.

\section{Análise e discussão dos resultados}

A seguir, vamos discutir os resultados referentes a dois tipos de dados: os coletados na observação participante e os resultantes da interação verbal com os jogadores.

Com base nas notas do diário de campo, vemos que o basquete de rua está numa encruzilhada, de caráter circunstancial. Ao se aproximar a Copa de 2014, a Cufa investe na Taça das Favelas, em parceria com a Unesco, com os ministérios da Saúde e do Esporte e com apoio de várias instituições públicas e de comunicação, com 80 seleções, 16 das quais formadas por moças. O projeto tem por objetivo atingir 24 mil jovens das favelas do Rio de Janeiro e valorizar o papel do jovem na cidade e as comunidades participantes do projeto.

O suporte vem para o futebol, e o basquete de rua fica em segundo plano. As vilas olímpicas instaladas nas favelas, como a do Complexo do Alemão e a da Mangueira, voltaram-se para acolher futebolistas. As quadras, polivalentes, convertem-se em espaços prioritários para o futebol.

Com base nas falas dos jogadores, temos em parte a mesma interpretação para a estagnação e diminuição do prestígio do basquete de rua. Constatamos, de acordo com o discurso dos praticantes, que a cultura do basquete de rua vem sucumbindo à universalização, abandonando as características da modalidade, voltando para o padrão, neste caso o basquete tradicional.

Das reflexões dos jogadores sobre a convivência entre um basquete supostamente mais livre e o basquete oficial, cresce o consenso de que as regras naturais são as do basquete convencional. Como em cada discussão a referência é a regra oficial, concluímos que o basquete de rua é, na verdade, um basquete convencional, jogado na rua; a ideia de 
basquete livre, para eles, traduz-se em um basquete onde a regra existe, mas há a alternativa de ajustá-la a cada jogada. Portanto, a percepção de basquete de rua para esses praticantes é o basquete que eles jogam, onde raramente aparece uma jogada característica do basquete de rua, como a caneta, o apagão ou crossover, e predominam as jogadas oriundas do basquete tradicional, que visam à cesta.

Ouvimos alguns relatos sobre a dificuldade em praticar a modalidade no Rio de Janeiro, com relação à manutenção do investimento em quadras públicas na cidade. Um jogador afirmou que são eles os responsáveis pela manutenção de algumas quadras, contribuindo na compra de aros, tabelas e na limpeza:

As poucas quadras que existem hoje, a gente costuma cuidar. A gente varre, a gente limpa, a gente dá aquela valorizada na quadra, pra poder manter.

As comunidades, por serem periféricas, não costumam receber investimentos e atenção governamental suficientes para atender às suas demandas. A atitude dos jogadores em serem eles próprios os mantenedores das quadras se justifica, pois eles sabem serem os responsáveis pela deteriorização desses locais.

As quadras nunca param, é sempre essa competição entre basquete, futebol, basquete, futebol. O futebol acaba arrebentando as quadras que tem, de basquete.

Os basqueteiros acertam acordos com os futebolistas em quadras existentes em escolas públicas da região onde moram, para que as duas práticas sejam realizadas em comum acordo e com divisões de tempo, aproveitando assim as boas condições oferecidas pelos responsáveis pelas quadras, sobretudo no caso de escolas. Um jogador relata:

Aqui só tem uma praça e [...] tem que dividir com todo mundo, aí aqui a gente consegue uma parceria, os meninos daqui conversaram com os diretores.

A utilização do espaço escolar, que é restrita aos fins de semana, ainda é uma alternativa tímida, mas viável, quando os jogadores estu- 
dam na escola e possuem um bom relacionamento com os responsáveis por ela, o que propiciou esse acordo.

No Rio de Janeiro, as organizações sociais foram responsáveis pela ascensão do basquete de rua. Porém, alguns participantes criticam o rumo que o esporte vem tomando na cidade. Questionados sobre o basquete de rua praticado na cidade e a avaliação positiva e negativa que fazem dele, os jogadores se dividem. Convergem sobre fato de o basquete de rua ter tido anos melhores, a partir de 2004 até o ano de 2010 , com relação a campeonatos e projetos implantados. Para eles o basquete teve seu auge quando os campeonatos se iniciaram a partir da Cufa, porém a partir de 2010 houve uma queda; segundo eles, "não é mais novidade". Há consenso em que o basquete vem crescendo ao longo dos anos, por conta dos projetos implantados pelas ONGs:

Acho que até cinco anos atrás deu uma levantada considerável, mas desses cinco anos pra cá deu uma estagnada. Tipo chegou ao auge e está mantendo.

A crítica dos praticantes é pertinente, pois diz respeito aos campeonatos realizados pela $\mathrm{Cufa}$, voltados para a modalidade, que diminuíram, deixando os jogadores receosos quanto ao interesse em incentivar a organização de campeonatos para a modalidade no estado. Conforme vimos, desde 2005 a Cufa realiza campeonatos de basquete de rua no Rio de Janeiro nos níveis municipal, estadual e nacional; porém, em 2010 e em 2011 apenas o campeonato nacional foi realizado. Os projetos promovidos pela LUB não ocorrem mais, segundo seu coordenador, por falta de verba e espaço para realizá-los. Os jogadores temem não terem mais o basquete de rua em nível de competição - o que ainda ocorre nos campeonatos realizados pela $\mathrm{Cufa}-$, tornando-se só uma pelada praticada nas comunidades. Há uns poucos campeonatos esporádicos, organizados pelos próprios jogadores com a participação dos times apenas do Rio de Janeiro.

\section{Considerações finais}

Procuramos utilizar a perspectiva de Magnani (2002), identificando, descrevendo e interpretando as práticas que ocorrem na modalidade do basquete de rua no Rio de Janeiro. 
O basquete de rua teve visibilidade depois que duas organizações sociais, a Cufa e a LUB, iniciaram projetos voltados para esse esporte na cidade, promovendo ações sociais e culturais através da modalidade. Enquanto a Cufa iniciou seus projetos organizando campeonatos de basquete de rua em âmbito nacional e estadual, a LUB voltou-se para a criação de um time de basquete de rua, no estilo Harlem Globetrotters, percorrendo comunidades, hospitais e escolas da cidade, fazendo apresentações de basquete espetáculo.

Contudo, essas mesmas organizações que elevaram o basquete nas favelas agora o abandonam para envolver-se com o futebol, o que se justifica pela proximidade da Copa do Mundo no Brasil.

O abandono é apontado e criticado pelos jogadores, que citam a diminuição de campeonatos voltados para a modalidade na cidade e apontam o desinteresse da esfera governamental para com esse esporte no Rio de Janeiro. Apontam, ainda, o fato de a Cufa voltar sua atenção para seu novo projeto para a comunidade futebolística, com suporte massivo de várias instituições públicas e privadas.

Durante a pesquisa, identificamos 14 comunidades onde se pratica a modalidade esportiva. Podemos garantir que essas comunidades se ajustam e reelaboram as regras do basquete oficial, com foco na criatividade e no caráter espetacular de jogadas individuais. Os praticantes criam as regras em suas comunidades, que são baseadas no modelo tradicional; entretanto, eles abrem mão dessas regras, cada vez que se defrontam com times de outras localidades e regiões, pois nesse caso predominam as regras do basquete convencional, com taxa de ajuste relativamente pequena.

Concluímos que o basquete de rua é, na interpretação deles, um basquete tradicional mais livre, com regras flexíveis, ajustadas às suas necessidades. É o basquete onde raramente aparece uma jogada característica do basquete de rua, sendo, neste caso, um basquete jogado "na" rua.

\title{
Streetball in the city of Rio de Janeiro
}

\begin{abstract}
The purpose of the study is to identify the source and describe the scenario of streetball in Rio de Janeiro. The research is slightly ethnographic, and uses notes from field, fragments of discourses of the players. We found that streetball is played on the streets and squares of several neighborhoods of the city. We focused on the space of the Central Única das Favelas, in Madureira Viaduct, where players from
\end{abstract}


different neighborhoods are gathered and the rules summarize and reinterpret the standards of other spaces where such type of basketball is played. Streetball is losing space to football projects.

Keywords: Ethnography. Game. Participation.

\section{Baloncesto en la ciudad de Rio de Janeiro}

\section{Resumen}

El objetivo del estudio fue identificar el origen y describir el escenario del baloncesto callejero en Rio de Janeiro. La investigación fue en parte basada en la etnografía. Basados en registros de apuntes diarios y de hablas de los deportistas y de un informante de elite, nos dimos cuenta que se practica baloncesto en las calles y plazas de variados barrios de nuestra ciudad. Pusimos atención en el espacio Central Única das Favelas, en el viaducto de Madureira, donde cada semana se encuentran deportistas de distintos barrios y donde las reglas reinterpretan las normas de otros espacios en que se practica esa modalidad de baloncesto, que pierde espacio para proyectos de fútbol.

Palabras clave: Etnografía. Juego. Participación.

\section{Referências}

CUFA. Regras oficiais da Liga Brasileira de Basquete de Rua: manual dos basqueteiros. Rio de Janeiro: Daijo Gráfica, 2008.

DAYRELL, J. O rap e o funk na socialização da juventude. Revista Educação e Pesquisa, São Paulo, v. 28, n. 1, p. 117-136, jan./jun., 2002.

DUARTE, R. J. B. O basquete de rua como manifestação da cultura corporal na cidade de Salvador. 2010. 92 f. Dissertação (Mestrado em Educação) - Faculdade de Educação, Universidade Federal da Bahia, Salvador, 2010.

FREITAS, A; VIEIRA, S. O que é basquete: história, regras, curiosidades. Rio de Janeiro: Casa da Palavra, 2006.

GUARESCHI, F.; MORAES, A. M. L.; PRATES, A. M. O universo paralelo: o hip hop como alternativa de reelaborar. Revista da Graduação, Porto Alegre, v. 1, n. 1, p. 1-24, jan./jul., 2008.

MAGNANI, J. G. C. De perto e de dentro: notas para uma etnografia urbana. Revista Brasileira de Ciências Sociais, São Paulo, v. 17, n. 49, p. 11-29, jun., 2002. 
OLIVEIRA FILHO, A. História do streetball. Rio de Janeiro, dezembro, 2006. Disponível em: <http://www.lub.org.br/pages/streetball/historia_do_streetball/images/Historia_Streetball_dez_15-Revisao_1.pdf>. Acesso em: 4 abr. 2011.

OSBORNE, R.; SILVA, C. A. F.; VOTRE, S. Educação física, esporte e desenvolvimento sustentável. Pensar a Prática, Goiânia, v. 14, n. 1, p. 1-14, jan./abr., 2011.

PINHEIRO, D. M. Fazendo arte no viaduto: considerações sobre o hip hop carioca. In: CONGRESSO DE CIÊNCIAS DA COMUNICAÇÃ̃O NA REGIÃO SUDESTE, 14., 2009, Rio de Janeiro. Anais... Rio de Janeiro: 2009.

SILVA, C. A. F.; CORREIA, A. M. Espetáculo e reflexividade: a dimensão estética do basquete de rua. Revista Brasileira de Ciências do Esporte, Campinas, v. 30, n. 1, p. 107-122, set., 2008.

SPINDOLA, B. Políticas de esporte para a juventude. São Paulo: Centro de Estudos e Memória do Esporte, 2008.

STIGGER, M. P. et al. (Org.). Esporte na cidade: estudos etnográficos sobre sociabilidades esportivas em espaços urbanos. Porto Alegre: Editora da UFRGS, 2007. 194 p.

Recebido em: 06/09/2011

Revisado em: 12/01/2012

Aprovado em: 23/03/2012

Endereço para correspondência

sebastianovotre@yahoo.com

Sebastião Votre

Universidade Gama Filho

Centro de Ciências Biológicas e da Saúde, Departamento de Educação Física.

Rua Manuel Vitorino, 625

Piedade

20748-900 - Rio de Janeiro, RJ - Brasil 